\title{
EVALUATION OF FABA BEAN VARIETIES GROWN WITH CRENATE BROOMRAPE (Orobanche crenata) IN PETRI DISH UNDER CONTROLLED ENVIRONMENT
}

\author{
*Lemma Diriba ${ }^{1}$, Firew Mekbib ${ }^{2}$ and Mussa Jarso $^{3}$ \\ ${ }^{1}$ Ethiopian Institute of Agricultural Research (EIAR) \\ ${ }^{2}$ Haramaya University, Department of Plant Sciences \\ ${ }^{3}$ Ethiopian Institute of Agricultural Research (EIAR)
}

https://doi.org/10.35410/IJAEB.2021.5628

\begin{abstract}
Orobanche Crenata is one of serious and dominant roots parasitic weed to legumes crop production in Ethiopia. It is a major constraint to faba bean (Vicia faba L.) production and causing total yield loss, especially at Northern parts of the country. So, there is a need to find new sources of resistance or identification means of resistance mechanisms to facilitate faba bean resistance breeding. Therefore, the aim of the study is to evaluate the level of resistance and to determine the host-parasite association selectively for O. crenata using Petri dish. Thus, 5 plants of twenty faba bean varieties are tested under controlled condition using completely Randomized Design (CRD) with three replications. The parasite seed is collected from the infested field and equally inoculated to faba bean in petri dish. The parasite growth stages and attachments was recorded weekly up to 70 DAI or 85 days host reached for maturity by using 15 scale under laboratory. All difference among treatments was analyzed by using Tukey's Standardized Range ( $<1 \%$ ) Test. The higher level of O. crenata infection was observed on highly susceptible varieties, during the parasite's growth stage 3,4 and 5. Accordingly, only 8 varieties were reached for maturity with number of seeds ranged 21-174 from 1-4 plants per Petri dishes; the remaining 12 varieties were completely destroyed before flowering and pod setting stage. The varieties are then grouped into different clusters with different sizes based on their degree of resistance or susceptibility. Three varieties 'Ashenge, Dedia and Obse' are selected for their best performance. Amongst, Ashenge variety is selected as partially resistant with highest yield provided (174 seeds from 4 plants) due to lower occurrence of parasite with it, whereas 'Dedia and Obse' selected as partially tolerant varieties with 106 and 84 seeds from 2 and 3 plants per petri dish respectively. Therefore, the future breeding program should be mainly focused on these three selected varieties to improve the problem of faba bean production by using conventional and molecular breeding methods.
\end{abstract}

Keywords: Inoculation, Orobanche crenata, Petri dish, resistance.

\section{INTRODUCTION}

Faba bean (Vicia faba L.) is a grain legume grown worldwide as a source of protein for both human food and animal feed. In addition to protein, faba bean is used to improve soil fertility as source of nitrogen available to the next crops in the rotation and soil from biological N2 fixation, 
Vol. 06, No. 03; 2021

ISSN: $2456-8643$

and a diversification of cropping systems. It needs a cool season for best growth with moderate rainfall of 650 to $1000 \mathrm{~mm}$ per annum (Gasim and Link, 2007) and considered to tolerate frost and acid soil conditions than most legumes (Singh et al., 2010) and can tolerate different soil types with pH 6.5 to 8.0 (Rajan et al., 2012), but are susceptible to drought and water logging (Subash and Priya, 2012). It has high nutritional value and is used almost daily in human diet of many Ethiopians as dry grains and green pods (Mussa et al., 2015). Faba bean is the fourth most important legume worldwide, after pea, chickpea and lentil (Yahia et al., 2012). The major productive area for faba bean in Ethiopia are Wollega, Shoa, Arsi, Bale, Gondar, Gojam, Wollo, Gamo Gofa and highland parts of Tigray (CSA 2016/17). The crop takes about four to five months for mature enough based on environmental condition (Mussa et al., 2008).

However, currently the production and productivity of faba bean is decreasing due to various biotic (diseases, insect pests, and parasite weeds) and abiotic (drought, salinity, fertility etc.) constraints (Sahile, 2008; Mussa et al., 2008). Amongst, Broomrapes (Orobanche spp.) are the one and series constraint of faba bean production which known by the aggressive root parasitic weeds and are completely dependent on the host due to the lack of chlorophyll and functional roots (true roots) (Eizenberg et al., 2010). Broomrapes can release more than 100,000 seeds from single stem, which are known to remain viable for decades in the soil (Eizenberg et al., 2010). This enables the parasite with a great genetic adaptability to host resistance, agronomical practices, herbicide treatments and environmental changes. Legumes are parasitized by many different species of broomrapes, however, Orobanche crenata is the most damaging and wide spread which has a wide host range among legumes crop in many temperate climates region (Rubiales, 2014). The damage caused by this parasite on faba bean crop is significant and it causes about 7 to $80 \%$ yield losses depending on the level of infestation (Maalouf et al., 2011). As they are root parasitic weeds, most of their infection and pathogenesis process take place underground, which complicates diagnosis of infection and control (Rubiales et al., 2009). Following germination, the seedlings attach to the host roots and grow at the expense of the host plant's resources (Joel et al., 2007).

In Ethiopia, the Orobanche infestations become quickly distributed over large area of cultivating lands. Northern parts of the country, especially Gonder, southern and western part of Wollo and southern Tigray were the most dominated area by this parasite. The estimated yield losses in faba bean due to Orobanche crenata is as high as reached 75 to $100 \%$ depending on host susceptibility, level of infestation and environmental conditions (Teklay et al., 2013).

The growth and development of broomrape, like that of the host plant is affected by the environmental conditions. The condition or soil temperature favor the growth of crop root system is also advantageous for the germination and attachment of broomrapes. Orobanche seeds only germinate in the proximity of roots of a suitable host in response to a germination stimulant compound present in the root exudate. However, before being able to respond to this external stimulus the seeds need to be exposed to moist conditions at a suitable temperature (20-25 0C) for a certain period of time. The difficulty and unidentifiable nature of Orobanche weed is make the farmers confused to control, and the only option they took is, planting other cereal crops instead of faba bean. Presently, the continuous spread of Orobanche limits the choice of rotational crops and often force farmers to stop up growing this most valuable crop (Teklay et al., 
2013). Thus, there is a need to find new sources of resistance and to understand the underlying resistance mechanisms in order to facilitate faba bean resistance breeding. Hence, evaluation for their performance by growing with Orobanche crenata under controlled environment is very important for more investigation to identify host roots-parasite association and to identify the critical time of parasite attachment to host roots. Therefore, the main objectives of this study are to evaluate the effects of Orobanche crenata infection on faba bean varieties and to determine the host-parasite association during growing stage.

\section{MATERIALS AND METHODS}

\subsection{Experimental Materials}

Twenty Faba bean varieties were obtained from different Agricultural Research Center in Ethiopia, listed in the following (Table 1). All varieties were evaluated under laboratory condition to determine the degree of crenate broomrape infection and its reaction with faba bean varieties using Petri dishes. The experiment was carried out by using completely randomized design (CRD) with three replications.

Table 1. Description of faba bean Varieties used for the study

\begin{tabular}{|llll|}
\hline No & Name of Varieties & Maintainer & Year of release \\
\hline 1 & Holetta-2 (BP 1802-1-2 & HARC & 2001 \\
2 & Selele (Selele kasim 91-13) & HARC & 2002 \\
3 & Wayu (Wayu 89-5) & HARC & 2002 \\
4 & Moti (EH 95078-6) & HARC & 2006 \\
5 & Gabelecho (EH96009-1) & HARC & 2006 \\
6 & Obse (EH 95073-1) & HARC & 2007 \\
7 & Welki (ETH 96049-2) & KARC & 2008 \\
8 & Dosha (Coll 155/00-3) & HARC & 2009 \\
9 & Mesay & HARC & 1995 \\
10 & Tumsa (EH-99051-3) & HARC & 2010 \\
11 & Hachalu (EH009102-4-1) & HARC & 2010 \\
12 & Bulga-70 & HARC & 1994 \\
13 & Degaga & HARC & 2002 \\
14 & Didea & HARC & 2014 \\
15 & Tesfa & HARC & 1995 \\
16 & Gachena (ETH 91001-13-2) & HU & 2008 \\
17 & Ashenge (Resistant)- check & Alemata ARC & 2014 \\
18 & Mosisea (EH-99047-1) & Sinana ARC & 2013 \\
19 & Aloshe & Sinana ARC & 2017 \\
20 & Shallo & Sinana ARC & 2000 \\
\hline
\end{tabular}

\subsection{Seed preconditioning and germination}


Vol. 06, No. 03; 2021

ISSN: $2456-8643$

Broomrape (Orobanche crenata) seeds were collected sufficiently (about $1.2 \mathrm{~g}$ ) from the field, where the faba bean varieties were previously cultivated. Approximately, about 30,000 seeds (in average 500 seeds per Petri dishes) of Orobanche crenata seeds were inoculated to each variety within three replications. The collected Orobanche seeds were sterilized for 7 min in sodium hypochlorite solution for avoiding contamination. They were preconditioned in the dark at $22{ }^{\circ} \mathrm{C}$ for one week.

Five faba bean seeds were taken from each varieties and they were also sterilized in sodium hypochlorite solution for 5 minute and washed (rinsed) several times in sterile distilled water, then germinated in Petri dishes on glass fiber filter paper moistened with water and maintained in the dark at $25{ }^{\circ} \mathrm{C}$ (Abbes et al., 2010). Faba bean seeds then germinated in small size of petri dishes.

\subsection{Orobanche crenata-faba bean cultures in petri dishes}

Petri dishes were prepared in sufficient and rinsed well. Germinated faba bean seeds were transferred to large square Petri dishes $(10 \times 20 \mathrm{~cm})$ after one week. The Petri dishes were placed vertically in plastic bowls $(30 \times 45 \mathrm{~cm})$. The culture bowls were placed in a growth chamber at 22 ${ }^{\circ} \mathrm{C}$ and incubated with a $12 \mathrm{~h}$ day and $70 \%$ relative humidity. The culture medium was replaced three times weekly (Abbes et al., 2010). Two weeks later, preconditioned seeds of O. crenata (about 500 seeds per petri dish) were placed homogeneously (uniformly) with a micropipette around the faba bean roots (1-3 mm away from either side of well-developed Faba bean roots) at an average density of 100 seeds per plant. The Orobanche seeds were carefully counted manually. Twenty- to- twenty five days after host root inoculation, percent Orobanche germination was assessed under a microscope by determining the mean number of seeds with an emerged radicle. After germination percentage was recorded, $60 \mathrm{~kg}$ of sterilized sandy soil and $9.6 \mathrm{~L}$ of sterilized water was prepared, and then $1 \mathrm{~kg}$ of soil mixed with $160 \mathrm{~mL}$ of water was applied in each petri dish $(10 \times 20 \mathrm{~cm})$. Faba beans grow well under these conditions. The experiment was conducted at Tigray Region Agricultural and Rural Development Office Seed Laboratory room 1 and 2, Mekele.

\subsection{Data collection under laboratory experiment}

Number of Orobanche seeds emerged- total Orobanhe seeds emerged per Petri dishes were counted and computed for their mean values.

Percent Orobanche germination (\%): it was measured by:

$$
\% \text { Orobanche germination }=\left(\frac{\text { Germinated Orobanche seeds }}{\text { Total Seeds innoculated }}\right) \times 100
$$

Number of broomrape attachments per host plant: the number Orobanche attachment to each plant per Petri dishes was recorded weekly up to the host plants reached for pod maturity. The broomrape growth stages were determined according to the 1-5 scale of Labrousse et al. (2001, 2004): 1-germination, prompted by stimulants that are produced by the roots of host plants; 2 attachment to the host vascular system by means of a haustorium, which serves as both an 
attaching organ and a bridge for water and nutrient transfer from the host; 3- tubercle establishment, with the formation of adventitious roots without shoot; 4- development of a subterranean shoot, and 5- development of flowering spikes. Broomrape attachment was followed weekly up to 85 days experiment duration, by counting the attached parasites on each host plant. Tubercle growth was also determined weekly by measuring the changes in tubercles' growth stage and reaching stage 5 in each host plant for the 85 days duration of the experiment.

\subsection{Data Analyses}

All collected data were subjected to ANOVA (one way ANOVA) by using SAS version 9.2. Means and coefficient of variation was used in order to compare variation between varieties or traits. The significance of the mean difference between varieties was evaluated by the Tukey's Standardized Range (HSD) Test at $\mathrm{P}<0.05$.

Cluster analysis: Cluster analysis was carried out for tested traits and grouping twenty faba bean varieties into different clusters based on their degree of resistance, at both conditions. All analyses were carried out using SAS statistical software version 9.2.

\section{RESULTS AND DISCUSSION}

\subsection{Analysis of variance}

The analysis of variance for faba bean varieties showed that there were highly significance differences $(\mathrm{P}<0.01)$ among tested faba bean varieties for percent Orobanche crenata seeds germination, number of Orobanche shoots emerged per petri dish, number of broomrape attachments per host, number of pods per plant, number of seed per pods and number of seeds per total plants (Table 2).

\subsection{Crenate Broomrape seed germination}

The percentage of $\mathrm{O}$. crenata seed germination near the faba bean roots was determined twenty five days after inoculation. The result of analysis indicated that the responses of faba bean varieties for Orobanche germination was highly significant $(\mathrm{P}<0.01)$ different among tested varieties (Table 2). The germination percentage ranged from 27 to $78 \%$ for the all faba bean varieties (Table 4). The lowest germination percentages occurred near the roots of the partially resistant and partially tolerant varieties, [Ashenge (37\%), Obse(54\%) and Dedia (55\%)], whereas the maximum percentage of broomrape germination occurred near the roots of highly susceptible varieties, i.e., Aloshe (78\%), Tesfa (77.67\%), Moti and Hachalu (75\%), Wayu and Tumsa (72\%) and Gebelcho (74\%). Inline to this study, Abbes et al., (2010) also reported that the higher percentage of Orobanche seed germination was near the roots of susceptible plants, but lowest in resistant varieties.

\subsection{Orobanche crenata attachments to faba bean roots}


The number of Orobanche attached per host-roots was highly significant $(\mathrm{P}<0.01)$ different among tested faba bean varieties (Table 2). The attachments of broomrape to faba bean plants and their growth stage was recorded weekly during 70 days after inoculation (DAI) or 85 days of the experiment duration. In susceptible varieties, the growth of $\mathrm{O}$. crenata was faster and higher in number of attachments than that of the resistant and partially tolerant varieties. The level of parasite attachment was also variety-dependent. The first broomrape attachments to host roots occurred in susceptible varieties and appeared already 35 DAI or at 2nd week after germination (WAG) and increased quickly in 3rd and 4th WAG, which is the time of host critical to pod setting-stage.

This might be due to high suitable host in response to a germination stimulant compound present in the root exudate. Inline to this study, Fernández-Aparicio et al., (2009) reported that Orobanche spp. seeds germinate in response to chemical signals exuded from host roots, susceptible cultivars produced high amount of stimulant that initiate parasite seeds germination and development. Accordingly, at the maximum levels of parasitism (Lmax), the higher number of Orobanche attached per host was recorded from variety Tesfa (9.87), Moti (9.5) and Aloshe (9.27), followed by Gebelcho and Tumsa (8.6), Wayu and Welki (8.4) varieties (Table 4 and figure $1 \& 2)$, which were highly susceptible varieties.

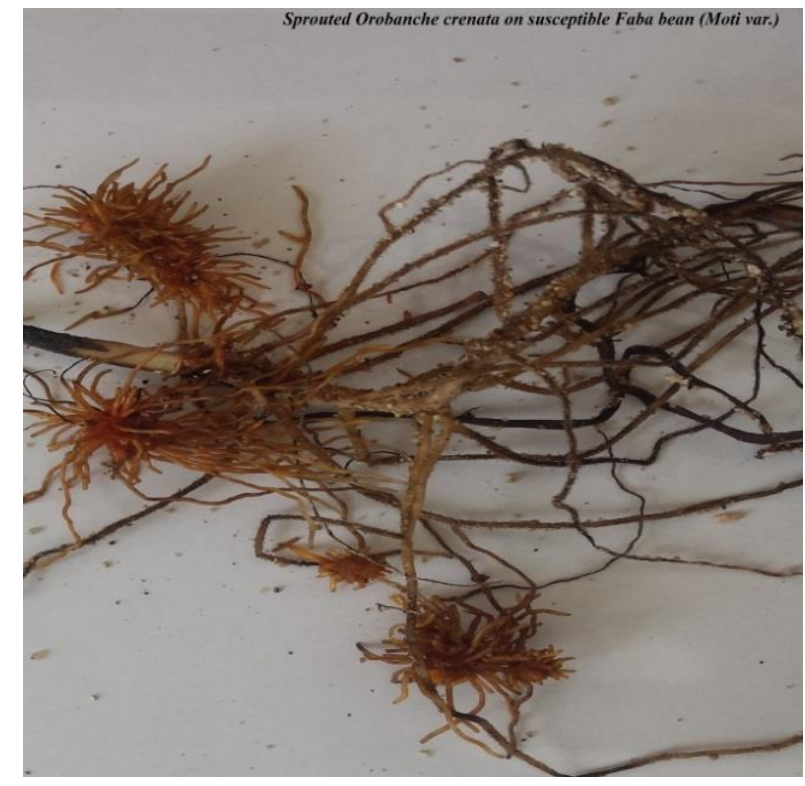

Figure 1. Orobanche crenata-faba bean roots association/attachments in highly susceptible variety

However, the number of attachments decreased at/ after 5th WAG in susceptible and highly susceptible varieties, because of the host-plants become delayed. In partially tolerant and resistant varieties "Ashenge (check), Dedia, Selale and Obse" the number of broomrape germination and attachments at Lmax of parasite was lower as compared with susceptible varieties; but, it increased further at/after 6th WAG (Table 3), when the hosts become physiologically matured. 




Figure 2. Level of Orobanche attachments on partially resistant/tolerant host root

This might be due to higher host- resistance mechanisms to prevent parasite germination, penetration and hampered development of established tubercles at host pod setting stage and lower at host pod maturity stage. In addition, on the other hands, resistance mechanisms might operate after haustoria formation preventing or retarding further development into a broomrape shoot, however, when host became to mature the ability to provide nutrient for biomass and production of metabolite chemicals which defend against parasite attachments become decreased.

\subsection{Emergence of Orobanche crenata and its growth stage}

The growth stage of Orobanche started from its germination of 25 DAI and continued in different ways of growth up to host maturity stage. In line with this study, Rubiales (2003) and Pérez-de-luque (2005) reported that the growth and development of broomrape varied among faba bean varieties. Orobanche growth stages was assessed weekly up to 70 DAI or 85 days host reach for pod maturity using 1-5 scale (Labrousse et al., 2001 and 2004). Once Orobanche seed germinated, it quickly proceeded to attach on host roots, elicited by stimulants that are secreted by the roots of host plants; and thoroughly attached to the host vascular system by means of a haustorium, which helps as both penetrating organ and a bridge for water and nutrient transfer from the host.

Tubercles establishments with the formation of adventitious roots also continued later, when the host conducive to attached tubercles relationship. Accordingly, in the 1st, 2nd and 3rd week after germination (WAG) there were substantial number of underground attachments (growth stages 1-4) for all faba bean varieties, however, at 4th and 5th WAG the emergence of spike (stage 5) took place on susceptible varieties, at which host-delayed (H-Dd) mainly occurred. But, in partial tolerance and/or resistance varieties the emergence of spike (stage 5) and development of flowering spikes was increased at 6th WAG (Table 3), when the host plants already reached for maturity. Most of the varieties, especially susceptible varieties, affected during the parasite growth stages 3 and 4, i.e. the underground infection did exert high influence on faba bean plants. 
Vol. 06, No. 03; 2021

ISSN: $2456-8643$

Table 2. Mean squares of tested traits from analysis of variance (ANOVA) for faba bean varieties grown with Orobanche crenata under Laboratory condition

\begin{tabular}{|lllll|}
\hline Characters & \multicolumn{2}{l}{ Source of variation } & Mean & $\mathrm{R}^{2}$ \\
\cline { 2 - 3 } & $\begin{array}{c}\text { Varieties } \\
(d f=19)\end{array}$ & $\begin{array}{l}\text { Error } \\
(d f=38)\end{array}$ & & \\
\hline Percent Orobanche seeds germination & $394.5^{* *}$ & 0.74 & 64.97 & 0.99 \\
Number of Orobanche emerged per petri dish & $81.43^{* *}$ & 0.4 & 23.97 & 0.99 \\
Number of broomrape attachments/host plant & $7^{* *}$ & 0.02 & 7.4 & 0.99 \\
Number of pods per plant & $36^{* *}$ & 0.02 & 1.87 & 0.99 \\
Number of seed per pods & $10.65^{* *}$ & 0.0 & 1.1 & 1.00 \\
Number of seeds per total plants & $6283.78^{* *}$ & 1.09 & 17.3 & 0.99 \\
\hline
\end{tabular}

The mean separation was evaluated by using Tukey's standardized range test, ** $=$ highly significant $(P<0.01), *=$ significant $(P<0.05), d f=$ degree of freedom and $R 2=$ coefficient of determination.

Table 3. Mean value of weekly recorded Orobanche growth stage (1-5) and their attachments after inoculated to host roots

\begin{tabular}{|c|c|c|c|c|c|c|c|c|c|c|c|c|}
\hline \multirow[t]{2}{*}{ Varieties } & \multicolumn{2}{|c|}{$1^{\text {st }} \mathbf{W A G}$} & \multicolumn{2}{|c|}{$2^{\text {nd }}$ WAG } & \multicolumn{2}{|c|}{$3^{\text {rd }}$ WAG } & \multicolumn{2}{|c|}{$4^{\text {th }}$ WAG } & \multicolumn{2}{|c|}{$5^{\text {th }} \mathrm{WAG}$} & \multicolumn{2}{|c|}{$6^{\text {th }} \mathrm{WAG}$} \\
\hline & GS & NA & GS & NA & GS & NA & GS & NA & GS & NA & GS & NA \\
\hline Holleta-2 & 2 & Un-Id & 3 & $4.5 b$ & 4 & 7.3de & 4 & 6.4hi & 5 & $5.4 \mathrm{c}$ & 5 & 2.4 \\
\hline Salale & 1 & Un-Id & 2 & $3.4 \mathrm{~d}$ & 3 & $4.47 \mathrm{j}$ & 4 & $5.3 \mathrm{j}$ & 5 & $6 b$ & 5 & $4.4 \mathrm{c}$ \\
\hline Wayu & 2 & Un-Id & 3 & $4.47 b$ & 4 & $8 c$ & 5 & $8.7 \mathrm{c}$ & 5 & $5.9 b$ & H-Dd & 0 \\
\hline Moti & 2 & 1.4 & 3 & $5.6 \mathrm{a}$ & 4 & $9.47 \mathrm{a}$ & 4 & $9.6 a b$ & H-Dd & $0 \mathrm{~g}$ & H-Dd & 0 \\
\hline Gebalcho & 2 & 1.00 & 3 & $4.6 \mathrm{~b}$ & 4 & $8.27 \mathrm{c}$ & 4 & $8.8 \mathrm{c}$ & H-Dd & $0 g$ & H-Dd & 0 \\
\hline Obse & 2 & Un-Id & 3 & $2.4 \mathrm{f}$ & 4 & $4.5 \mathrm{j}$ & 4 & $6.3 \mathrm{i}$ & 5 & $6.7 \mathrm{a}$ & 5 & $4.6 c$ \\
\hline Welki & 2 & Un-Id & 3 & $3.4 \mathrm{~d}$ & 4 & $6.7 \mathrm{e}$ & 5 & $10.3 \mathrm{a}$ & 5 & $5.4 \mathrm{c}$ & 5 & $1.6 \mathrm{~d}$ \\
\hline Dosha & 2 & 1.2 & 2 & $4.27 b$ & 3 & $7.2 \mathrm{de}$ & 4 & $8.3 \mathrm{~cd}$ & 5 & $5 d$ & H-Dd & 0 \\
\hline Mesay & 1 & Un-Id & 2 & $3 e$ & 3 & $5 \mathrm{i}$ & 4 & $8.4 \mathrm{~cd}$ & 5 & $5 d$ & 4 & $1.5 \mathrm{~d}$ \\
\hline Tumsa & 2 & 1.00 & 2 & $4.2 b$ & 3 & $7.6 \mathrm{~d}$ & 4 & $9.6 \mathrm{ab}$ & 4 & $4 f$ & H-Dd & 0 \\
\hline
\end{tabular}


Vol. 06, No. 03; 2021

ISSN: $2456-8643$

\begin{tabular}{|c|c|c|c|c|c|c|c|c|c|c|c|c|}
\hline Hachalu & 2 & 1.2 & $\mid 2$ & $3.7 \mathrm{c}$ & 3 & 6.4ef & $\mid 4$ & $8.4 \mathrm{~cd}$ & H-Dd & $0 \mathrm{~g}$ & H-Dd & 0 \\
\hline Bulga-70 & 2 & Un-Id & 2 & $3.5 \mathrm{~cd}$ & 3 & $5.4 \mathrm{~h}$ & 3 & $7.7 \mathrm{fg}$ & 4 & $4.7 \mathrm{e}$ & H-Dd & 0 \\
\hline Degaga & 1 & Un-Id & 2 & $3.4 \mathrm{~d}$ & 3 & $6.3 \mathrm{fg}$ & 4 & $6.8 \mathrm{hi}$ & 5 & $4.9 \mathrm{~d}$ & H-Dd & 0 \\
\hline Dedia & 1 & Un-Id & 1 & $2.27 f$ & 2 & $5 \mathrm{i}$ & 2 & $5.2 \mathrm{j}$ & 3 & $5.8 \mathrm{~b}$ & 3 & $5.3 b$ \\
\hline Tesfa & 2 & 1.6 & 3 & $5.47 \mathrm{a}$ & 4 & $9.67 \mathrm{a}$ & 4 & $10.2 \mathrm{a}$ & H-Dd & $0 \mathrm{~g}$ & H-Dd & 0 \\
\hline Gachana & 1 & Un-Id & 2 & $3.7 \mathrm{c}$ & 3 & $7.5 \mathrm{~d}$ & 4 & $7.1 \mathrm{gh}$ & 4 & $4.9 \mathrm{~d}$ & H-Dd & 0 \\
\hline Ashange & 1 & Un-Id & & $1.2 \mathrm{~g}$ & 1 & $2.7 \mathrm{k}$ & 2 & $3.7 \mathrm{k}$ & 2 & $4.9 \mathrm{~d}$ & 3 & $6.2 \mathrm{a}$ \\
\hline Mosise & 1 & Un-Id & 2 & $2.7 \mathrm{ef}$ & 3 & $6 \mathrm{~g}$ & 4 & $8 \mathrm{ef}$ & 5 & $5.3 \mathrm{c}$ & H-Dd & 0 \\
\hline Aloshe & 2 & 1.47 & 3 & $5.4 \mathrm{a}$ & 4 & $9 b$ & 4 & $9.4 \mathrm{bc}$ & H-Dd & $0 \mathrm{~g}$ & H-Dd & 0 \\
\hline Shallo & 1 & Un-Id & 2 & $3.5 \mathrm{~cd}$ & 3 & $6.2 \mathrm{fg}$ & 4 & $7.7 \mathrm{fg}$ & 5 & $5.5 \mathrm{c}$ & H-Dd & $0 \mathrm{e}$ \\
\hline $\mathrm{CV}$ & & 5.8 & & 2.08 & & 1.74 & & 2.78 & & 1.8 & & 2.85 \\
\hline
\end{tabular}

$D A I=$ Days after inoculation, $W A G=$ Week after germination, $G S=$ growth stage, $N A=$ number of attachments, $H D d .=$ Host delayed, Un Id = Unidentified, $C V=$ Coefficient of variation. Means with the same letter per column are not significantly different.

\subsection{Performance of faba bean in Petri dishes}

\subsubsection{Number of pods per plant}

The analysis of variance indicated that there were highly significant variations $(\mathrm{P}<0.01)$ in number of pods plant-1 (Table 2) between faba bean varieties. The maximum number of pods per plant 11.00 was obtained from Ashenge variety followed by Dedia and Obse varieties with 8.7 and 8.00 pods respectively. In highly susceptible varieties there was no any produced pod, due to host-delayed before pod setting, while in susceptible varieties (Holleta-2, Selale, Welki, Mesay and Degaga) the pods per single plant were produced in minimum amounts (Table 4).

\subsubsection{Number of seeds per pod}

There were few faba bean varieties that performed with seed setting under O. crenata infection in petri dishes that most of the varieties were delayed before flowering and other few of them were delayed at pod setting. However, 'Ashenge, Dedia, Obse, Welki, Mesay, Holetta-2 and Selale' reached for seed setting, in which the maximum (4 seeds per pod) was recorded from Ashenge, Dedia, Obse, Welki and (3.67 seed per pod) was from variety Mesay. The lower number of seeds per pod 3 was observed at Holetta-2 and Selale varieties (Table 4). But, these susceptible 
varieties produced about 10-15 pods per plant and 3.2 to 4.3 seed per pod under non Orobanche infestation area (Ashenafi et al., 2015).

\subsubsection{Number of seeds per total plants}

There were highly significant $(\mathrm{P}<0.01)$ different among faba bean varieties in plant reached for maturity per petri dish and in seeds recorded from them (Table 2). Determination for the number of plants reached for pod maturity was used to identify the degree of hostsusceptibility/resistance to parasite. Accordingly, the maximum number of seeds (174) per total plants (from 4 out of 5 plants) was recorded from Ashenge (resistance control), while the total seeds obtained from 'Dedia' variety was 106, in which the plants reached for maturity was 3 out of 5 plants, followed by 'Obse' (84) variety from 2 plants of 5 grown in petri dish. Whereas, the number of seeds per total plants recorded from Selale, Welki, Mesay, Holetta-2 (from 2/5 plants) and Degaga (from 1/5 plants) was 28, 24, 23, 21 and 18, respectively (Table 4).

\subsection{Cluster analysis}

Cluster analysis was conducted to grouping twenty tested faba bean varieties into different clusters based on their degree of resistance/susceptibility to broomrape infection. Thus, cluster analysis of varieties distinguished three degree of resistance classes of different sizes (Table 5), the varieties which had related degree of resistance categorized under the same cluster. Accordingly, most of the varieties (17) were grouped in cluster-1 as susceptible varieties, but twelve of them were the varieties which completely destroyed, while five of them were established with minimum seeds. The second and third clusters included partially tolerant and resistant varieties, respectively, but, only a single variety 'Ashenge' occurred in cluster-3.

Table 4. Performance of faba bean varieties grown with Orobanche crenata and determinations of parasitism levels

\begin{tabular}{|c|c|c|c|c|c|c|c|}
\hline $\begin{array}{l}\text { Faba } \\
\text { bean } \\
\text { varieties }\end{array}$ & $\begin{array}{l}O . \text { crenata } \\
\text { seed } \\
\text { germination } \\
\text { percentage }\end{array}$ & $\begin{array}{l}\text { No. of } O . \\
\text { emerged per } \\
\text { host at } L_{\max } \\
\text { of parasitism }\end{array}$ & $\begin{array}{l}\text { No. of } O . \\
\text { shoots(spikes) } \\
\text { emerged per } \\
\text { petri dish }\end{array}$ & $\mathrm{SCM}$ & NPP & NSP & NSPTP \\
\hline Holleta-2 & $62.3 \mathrm{~h}$ & $6.8 \mathrm{de}$ & $18.67 \mathrm{i}$ & $1.67 \mathrm{c}$ & $3 e$ & $3 b$ & $18 \mathrm{~g}$ \\
\hline Salale & $62.67 \mathrm{gh}$ & $5.67 f$ & 19hi & $2 c$ & $5 d$ & $3 b$ & $28 d$ \\
\hline Wayu & $72.3 c$ & $8.37 b$ & $25 \mathrm{e}$ & $0 \mathrm{e}$ & Of & $0 \mathrm{c}$ & $\mathrm{Oh}$ \\
\hline Moti & $75 b$ & $9.53 \mathrm{a}$ & $28 \mathrm{~cd}$ & $0 \mathrm{e}$ & Of & $0 \mathrm{c}$ & $\mathrm{Oh}$ \\
\hline Gebalcho & $74.67 b$ & $8.6 b$ & $27.67 \mathrm{~cd}$ & $0 \mathrm{e}$ & Of & $0 \mathrm{c}$ & $\mathrm{Oh}$ \\
\hline Obse & $54 \mathrm{j}$ & $6.37 \mathrm{e}$ & 20ghi & $2 \mathrm{c}$ & $8 \mathrm{c}$ & $4 a$ & $84 c$ \\
\hline Welki & $61 \mathrm{hi}$ & $8.47 b$ & $22 \mathrm{fg}$ & $2 c$ & $3 e$ & $4 a$ & $24 \mathrm{e}$ \\
\hline Dosha & $69 d$ & $7.57 b c$ & $26 \mathrm{e}^{\circ}$ & $0 \mathrm{e}$ & Of & $0 \mathrm{c}$ & $\mathrm{Oh}$ \\
\hline Mesay & $59.3 \mathrm{i}$ & $7.2 \mathrm{dcd}$ & 19.3hi & $2 \mathrm{c}$ & $3 e$ & $3.67 \mathrm{a}$ & $23 \mathrm{e}$ \\
\hline Tumsa & $72 c$ & $8.6 b$ & $31 \mathrm{ab}$ & $0 \mathrm{e}$ & Of & $0 \mathrm{c}$ & $\mathrm{Oh}$ \\
\hline Hachalu & $75 b$ & $7.4 \mathrm{c}$ & $29 b c$ & $0 \mathrm{e}$ & Of & $0 \mathrm{c}$ & $\mathrm{Oh}$ \\
\hline Bulga-70 & $65 f g$ & $6.5 \mathrm{e}$ & $24 \mathrm{ef}$ & $0 \mathrm{e}$ & Of & $0 \mathrm{c}$ & Oh \\
\hline
\end{tabular}


Vol. 06, No. 03; 2021

ISSN: $2456-8643$

\begin{tabular}{|llllllll|}
\hline Degaga & $68.67 \mathrm{de}$ & $6.5 \mathrm{e}$ & $25 \mathrm{e}$ & $1 \mathrm{~d}$ & $5 \mathrm{~d}$ & $4 \mathrm{a}$ & $21 \mathrm{f}$ \\
Dedia & $55 \mathrm{j}$ & $5.53 \mathrm{f}$ & $18 \mathrm{i}$ & $3 \mathrm{~b}$ & $8.7 \mathrm{~b}$ & $4 \mathrm{a}$ & $106 \mathrm{~b}$ \\
Tesfa & $77.67 \mathrm{a}$ & $9.87 \mathrm{a}$ & $32 \mathrm{a}$ & $0 \mathrm{e}$ & $0 \mathrm{f}$ & $0 \mathrm{c}$ & $0 \mathrm{~h}$ \\
Gachana & $66.3 \mathrm{ef}$ & $7.27 \mathrm{~cd}$ & $27.67 \mathrm{~cd}$ & $0 \mathrm{e}$ & $0 \mathrm{f}$ & $0 \mathrm{c}$ & $0 \mathrm{~h}$ \\
Ashange & $27 \mathrm{k}$ & $3.5 \mathrm{~g}$ & $12.67 \mathrm{j}$ & $4 \mathrm{a}$ & $11 \mathrm{a}$ & $4 \mathrm{a}$ & $174 \mathrm{a}$ \\
Mosise & $61.67 \mathrm{hi}$ & $6.8 \mathrm{de}$ & $20.3 \mathrm{ghi}$ & $0 \mathrm{e}$ & $0 \mathrm{f}$ & $0 \mathrm{c}$ & $0 \mathrm{~h}$ \\
Aloshe & $78 \mathrm{a}$ & $9.27 \mathrm{a}$ & $31.67 \mathrm{a}$ & $0 \mathrm{e}$ & $0 \mathrm{0}$ & $0 \mathrm{c}$ & $0 \mathrm{~h}$ \\
Shalo & $67.3 \mathrm{def}$ & $6.8 \mathrm{de}$ & $21.3 \mathrm{gh}$ & $0 \mathrm{e}$ & $0 \mathrm{c}$ & $0 \mathrm{c}$ & $0 \mathrm{~h}$ \\
\hline $\mathrm{CV}(\%)$ & 1.32 & 2.07 & 2.67 & & 5.5 & 8.7 & 1.08 \\
\hline
\end{tabular}

Lmax. $=$ maximum level, $S C M=$ Stand count at maturity, $N P P=$ number of pods per plant, $N S P$ $=$ number of seed per pod, NSPTP $=$ number of seed per total plants and CV=Coefficient of variation. Means with the same letter per column are not significantly different.

Table 5. Grouping 20 faba bean varieties tested under laboratory condition into different clusters based on their responses to Orobanche crenata infection.

\begin{tabular}{|l|l|c|l|}
\hline Clusters & Degree of resistance & No. of varieties & Description \\
\hline Cluster 1 & Susceptible & 17 & $\begin{array}{l}\text { Moti, Gebelcho, Tesfa, Aloshe, Tumsa, } \\
\text { Hachalu, Welki, Mesay, Wayu, Bulga-70, } \\
\text { Gachena, Mosise, Shallo, Dosha, Degaga, } \\
\text { Selale and Holetta-2 }\end{array}$ \\
\hline Cluster 2 & Partially tolerant & 2 & Obse and Dedia \\
\hline Cluster 3 & Partially resistant & 1 & Ashenge (resistance control) \\
\hline
\end{tabular}




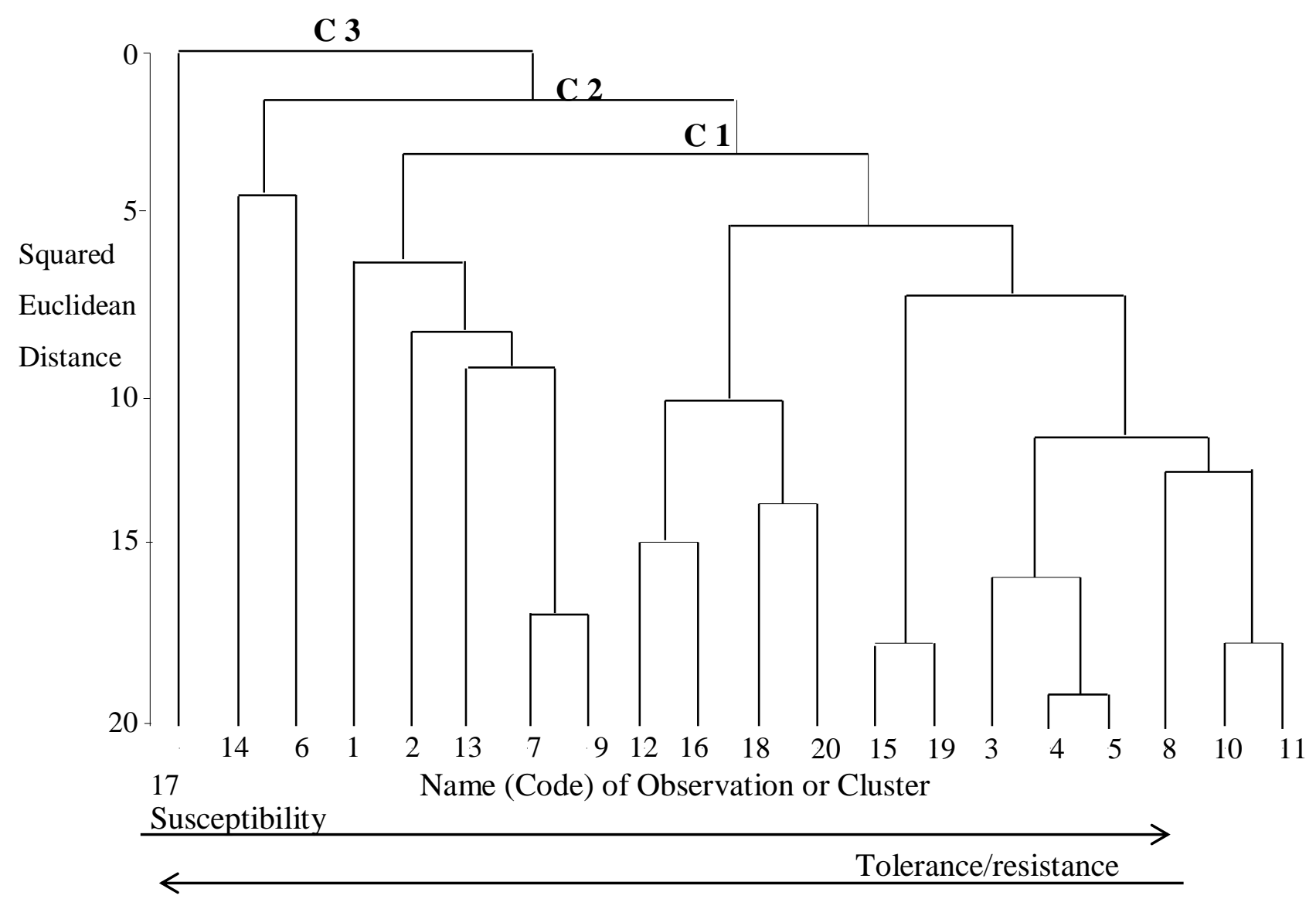

Figure 3. Dendrogram of 20 faba bean varieties evaluated for Orobanche crenata

\subsection{Infection level of Orobanche crenata on faba bean varieties and degree of host-plant resistance}

The parasite-host roots association and the influence of culture conditions on faba bean growth was variety-dependent, that they showed variation in their performance and degree of resistance/tolerance. In susceptible varieties the percentage of $O$. crenata seed germination was highest near host-roots with germination percentage ranged from $59-78 \%$. The total number of attached tubercles per plant depends on the rate of broomrape seed germination and its success in attaching itself to the host, which correlates with the resistance level of faba bean. Accordingly, the maximum level (Lmax) of parasite attachments was occurred in susceptible varieties. The growth stage of $\mathrm{O}$. crenata or established tubercles was also determined by using 1-5 scale (Labrousse et al., 2001).

Most of susceptible varieties become delayed before flowering when the parasite reached growth stage 4 , whereas some of them delayed during pod setting stage. The variation in broomrape germination and growth might be due to different in stimulant produced by host plants, in which 
the Orobanche spp. requires stimulants to germinate; any low germination probably derives from a low production of stimulants (Yoneyama et al., 2008). Thus, the varieties which produce high amount of stimulants were known to be highly susceptible varieties.



Figure 4. Indication of Orobanche crenata attachments and host-plant death in highly susceptible varieties

In partially tolerant varieties such as 'Dedia and Obse' the parasite germination percentage was 54 and 55\% respectively. The number of Orobanche attachments to the roots of these varieties also high when compared with resistant varieties. The number of attached broomrape at maximum level (Lmax) with 'Dedia' and 'Obse' was started when the varieties become to flowering and continued up to pod maturing stage. The host attempts to perform normally even attacked by Orobanche infestation. A host may be susceptible (i.e., support a high population of parasite) and yet exhibit little reduction in performance and yield. Because of tolerance is measured in terms of economic yield, it is not applicable to parasite and other damaging factors that directly attack the economic part of the plant. This due to the fact of resistance mechanisms that operate to reduce the levels of infection by the parasite, tolerance (or endurance) operates to reduce the extent/level of damage inflicted/ caused by damaging factors.

In partially resistant varieties, especially Ashenge variety, which had only a low capacity to bring about broomrape seed germination, the growth of O. crenata was slow and lowest in number of attachments than that of other varieties, and the plants did not favor the growth of established tubercle. This might be explained by mechanism of host defense (Pérez-De-Luque et al 2008). According to Abbes et al. (2010), the slow rate of broomrape attachment was due to physical and/or chemical barriers in the roots of the resistant varieties. Similarly, Zaitoun et al. (1991) also reported that the attachment of O. crenata to faba bean roots can be limited by the growth of 
Vol. 06, No. 03; 2021

ISSN: $2456-8643$

corky tissue at the site of penetration. Resistance faba bean roots had a slightly thicker epidermis, cortex and xylem, and an intact endodermal layer with thick walls, when compared with the roots of a susceptible faba bean cultivar (Khalaf and El-Bastawesy, 1989; Attia, 1991). In addition, the degree of resistance derived from a low production of stimulants by host plants. Nassib et al. (1978) and Wegmann et al. (1991) also reported that a low level of stimulants is essential for the resistance of faba bean to O. crenata. In this study, the same reason can be attributed for the resistance 'Ashenge' variety.

Generally, the level of parasitism to faba bean varieties determined by the time of Orobanche attachments to host plants that the first attachment occurred at susceptible varieties, and the amount of parasites attached to single plant. The early attachment to the roots of the host not only led to a high rate of broomrape attachment, but also resulted in a high infection for the susceptible varieties, as compared with the resistant varieties. Abbes et al. (2010) also reported that the highest percentage of broomrape seed germination and early attachment was occurred at the roots of the suscep $\neg$ tible faba bean.

\section{SUMMARY, CONCLUSIONS AND RECOMMENDATION}

The effect level of broomrape on faba bean varieties was evaluated by using different parameters on five randomly taken faba bean plants and sown in each petri dish at five Orobanche-growing stages (weekly recorded parasite-host attachment for $70 \mathrm{DAI}$ ). The to $\neg$ tal number of attached Orobanche per plant depends on the rate of broomrape seed germination and its success in attaching itself to the host, which correlates with the resistance level of faba bean. Accordingly, the maximum level (Lmax) of parasite attachments occurred in highly susceptible and intermediate susceptible varieties when compared with partially tolerant or resistant varieties. This was due to different in host resistance mechanism and stimulant produced by host plant. Susceptible varieties produced high stimulant that initiate the parasite seed germination and favourable to tubercles attachment to host plants with the end result of total yield loss.

Meanwhile, partially resistant of 'Ashenge variety' did not favor the growth of established tubercles, only a small percentage of established tubercles reached growth stage 5, unlike with the other varieties. This also might be due to host defense mechanisms/chemical which used as preventing the parasite seed germination. Contrary to Ashenge variety, the continuous parasite attachment was occurred on roots and the growth of established tubercles reached stage 5 in maximum percentage in Dedia and Obse varieties. But, these varieties yet stayed with good performance as compared with that of the other varieties. This situation makes these two varieties as considered as "Tolerant variety" because the host attempts to perform normally even attacked by Orobanche infestation and yet exhibit little reduction in performance and economic yield.

The extent and pattern of faba bean performance was also determined by cluster analysis for tested varieties, and faba bean varieties were grouped into three clusters with different number in each cluster. Varieties with complete (100\%) yield loss were grouped in cluster-1 (as highly susceptible); varieties from which medium yield obtained were grouped in cluster-2 (as intermediate/partial tolerance) and varieties with higher yield were grouped in cluster-3 (as partial resistance). 
Vol. 06, No. 03; 2021

ISSN: $2456-8643$

In this study, although the levels effect of broomrape to faba bean plants and the degree of hostresistance was tested, there was no determination about chemical produced from host plant to initiate or prevent the parasite seed germination. In addition, there was no clear evidence for the existence of host-specific races of $\mathrm{O}$. crenata. Thus, more studies are needed to determine what happens when faba bean is challenged with O. infestation, especially about deposition of obstructing compounds in the root xylem vessels of the host and mechanisms of resistance (stimulant chemical in susceptible varieties and/or defense chemical in resistant varieties). Breeding for resistance is, therefore, the most economic, feasible and environmental friendly method of control to improve the crop production. In this investigation, the Orobanche seed germination percentage, growth stage and its attachments to host plant, especially at host pod setting stage were the appropriate screening methods and effective selection indices. Therefore, future studies and research works needed to investigate further the parasite-host reaction across a location and should mainly targeted on the improvement faba bean plants by re-evaluation of partially resistant and tolerant varieties gained by this finding and crossing Ashenge variety with Dedia variety or Ashenge with Obse variety if positive response will obtained accordingly, including molecular analysis using QTLs and MAS, and biochemical studies to solve this serious problems and to provide high yielding faba bean material with tolerant or resistance to Orobanche spp.

\section{REFERENCES}

Abbes Z, Kharrat M, Pouvreau JB and Delavault P, 2010. The dynamics of faba bean (Vicia faba L.) parasitism by Orobanche foetida. Phytopathol. Mediterr, 239-248.

Ashenafi Mitiku andMekuria Wolde, 2015. Effect of Faba Bean (Vicia faba L.) Varieties on Yield Attributes at Sinana and Agarfa Districts of Bale Zone, Southeastern Ethiopia. Jordal Journal of Biological Science, 8(4), 281-286.

Attia SM, 1991. Response of some faba bean (Vicia faba L.) varieties to broomrape (O. crenata Forsk.). Ph.D. Thesis, Faculty of Agriculture, University of Cairo, Egypt, 73 pp.

CSA (Central Statistical Agency), 2017. The Federal Democratic Republic of Ethiopia. Agricultural Sample Survey Vol. I Report on Area and Production of Major Crops, private holdings for the 2016/17 meher season.

Eizenberg H, Grenz JH, Sillero JC and Carmen A, 2010. Broomrape management in faba bean. Field Crops Research 115, 319-328.

Fernández-Aparicio M, Flores F and Rubiales D, 2009. Recognition of root exudates by seeds of broomrape (Orobanche and Phelipanche) species. Annals Botany, 103: 423-431.

Fernández-Aparicio M, Moral A, Kharrat M and Rubiales D, 2012. Resistance against broomrapes (Orobanche and Phelipanche spp.) in faba bean (Vicia faba L.) based in low induction of broomrape seed germination. Euphytica, 186: 897-905.

Gasim S, Link W, 2007. Agronomic performance and the effect of soil fertilization on German winter faba bean. Journal of Central Europe Agriculture, 8:121-127. 
Vol. 06, No. 03; 2021

ISSN: $2456-8643$

Joel DM, Hershenhorn J, Eizenberg H, Aly R, Ejeta G, Rich PJ, Ransom JK and Sauerborn J, Rubiales D, 2007. Biology and management of weedy root parasites. Horticultural Reviews, 33: 267-349.

Khalaf K, FI El-Bastawesy, 1989. Some studies of the basis of resistance of Vicia faba cultivar Giza 402 to Orobanche crenata parasitism. FABIS Newsletter 25, 5-9.

Labrousse P, Arnaud MC, Serieys H, Berville A and Thalouarn P, 2001. Several mechanisms are involved in resistance of Helianthus to Orobanche cumana Wallr. Annals of Botany 88, 859-868.

Labrousse P, Arnaud MC, Griveau Y, Fer A and Thal-7ouarn P, 2004. Analysis of resistance criteria of sunflower recombinant inbred lines against Orobanche cumana Wallr. Crop Protection 23, 407-413.

Maalouf F, Khalil S, Ahmed S, Akintunde AN, Kharrat M, Hajjar S and El Shama'a K, 2011. Yield stability of faba bean lines under diverse broomrape prone production environments. Field Crop Res. 124, 288-294.

Mussa Jarso, Dereje Gorfu, and Gemechu Keneni, 2008. Procedures of Faba Bean Improvement through Hybridization. P. 48. Technical Manual No. 21, EIAR.

Nassib AM, Ibrahim AA and Saber HA, 1978. Broom $\neg$ rape (Orobanche crenata) resistance in broad beans. In: Workshop on Seed Legumes, ICARDA, Aleppo, Syria, 133-135.

Pérez-De-Luque A, Jorrín J, Cubero JI and Rubiales D, 2005. Orobanche crenata resistance and avoidance in pea (Pisum spp.) operate at different developmental stages of the parasite. Weed Research, 45: 379-387.

Pérez-De-Luque A, Moreno MT and Rubiales D, 2008. Host plant resistance against broomrapes (Orobanche spp.): defence reactions and mechanisms of resistance. Annals of Applied Biology, 152: $131-141$.

Rajan K, Singh AK, and Pandey AK, 2012. Faba bean soils and there management for higher productivity In: Faba Bean (Vicia faba L): A potential leguminous crop of India (Eds. Singh and Bhatt). ICAR, RC for ER, Patna, pp. 205-212.

Rubiales D and Pérez-de-luque A, 2003. Crenate broomrape (Orobanche crenata) infection in field pea cultivars Crenate broomrape (Orobanche crenata) infection in field. Crop Protection 22: 865-872.

Rubiales D, Fernández-Aparicio M, Pérez-De-Luque A, Prats E, Castillejo MA, Sillero JC, Rispail N and Fondevilla S, 2009. Breeding approaches for crenate broomrape (Orobanche crenata Forsk.) management in pea (Pisum sativum L.). Pest Management Science, 65: 553-559.

Rubiales D, 2014. Legume breeding for broomrape resistance. Czech Journal of Genetics and Plant Breeding, 50(2), 144-150. 
Vol. 06, No. 03; 2021

ISSN: $2456-8643$

Singh AK, Chandra N, Bharati RC and Dimree SK, 2010. Effect of seed size and seeding depth on faba bean (Vicia faba L.) productivity. Environmental Ecology 28(3A):1722-1527.

Subash N and Priya N, 2012. Climatic requirements for optimizing Faba bean (Vicia faba L.) production In: Faba Bean (Vicia faba L) An Potential legume for India. Eds. Singh and Bhatt. ICAR, RC for ER, Patna, pp. 197-204.

Teklay Abebe, Hadas Beyene and Yemane Nega, 2013. Distribution And Economic Importance Of Broomrape (Orobanche Crenata) In Food Legumes Production Of South Tigray, Ethiopia. ESci Journal of Crop Production, 2(3)101-106.

Wegmann K, Von Elert E, Harloff HJ, Stadler M, 1991. Tolerance and resistance to Orobanche. In: Pro $\neg$ ceedings of the Second International Workshop on Oro $\neg$ banche Research, Obermarchtal, Germany, 318-321.

Yahia Y, Guetat A, Elfalleh W, Ferchichi A and Yahia H, 2012. Analysis of agromorphological diversity of southern Tunisia faba bean (Vicia faba L.) germplasm, African Journal of Biotechnology, 11(56): 11913-11924.

Yoneyama K, Xie X, Sekimoto H, Takeuchi Y, Oga $\neg$ sawara S, Akiyama K and Hayashi H, 2008. Strigolactones, host recognition signals for root parasitic plants and arbuscular mycorrhizal fungi, from Fabaceae plants. New Phytologist 179, 484-494.

Zaitoun FMF, Al-Menoufi OA and Weber HC, 1991. Mechanisms of tolerance and susceptibility of three Vicia faba varieties to the infection with Orobanche crenata. In: Proceedings of the the Fifth International Symposium on Parasitic Weeds (J.K. Ransom, L.J. Mus $\neg$ selman, A.D. Worsham, C. Parker, ed.), CIMMYT, Nai`robi, Kenya, 195-207. 